\title{
Jeff Porter, Lost Sound: The Forgotten Art of Radio Storytelling
}

\section{Katherine Marazi}

\section{(2) OpenEdition}

\section{Journals}

Electronic version

URL: https://journals.openedition.org/ejas/12171

DOI: 10.4000/ejas.12171

ISSN: 1991-9336

\section{Publisher}

European Association for American Studies

\section{Electronic reference}

Katherine Marazi, "Jeff Porter, Lost Sound: The Forgotten Art of Radio Storytelling", European journal of American studies [Online], Book reviews, document 6, Online since 01 August 2017, connection on 31 August 2022. URL: http://journals.openedition.org/ejas/12171 ; DOI: https://doi.org/10.4000/ejas. 12171

This text was automatically generated on 31 August 2022.

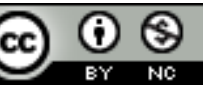

Creative Commons - Attribution-NonCommercial 4.0 International - CC BY-NC 4.0

https://creativecommons.org/licenses/by-nc/4.0/ 


\title{
Jeff Porter, Lost Sound: The Forgotten Art of Radio Storytelling
}

\author{
Katherine Marazi
}

Jeff Porter, Lost Sound: The Forgotten Art of Radio Storytelling

2 Chapel Hill: University of North Caroline Press. 2016. ISBN: 978-1-4696-2777-9.

3 Katherine Marazi

4 Aristotle University of Thessaloniki, Greece

5 In an age of visual and internet culture, not much thought goes to certain media, like the radio. Fortunately, there are certain respectable publications that draw our attention to storytelling capabilities of radio, provide concise historical overviews of radio as narrative medium, as well as interpretive analysis of the interplay between the radio's storytelling and sound capacity and how it was influenced by modernist literature. Jeff Porter's Lost Sound: The Forgotten Art of Radio Storytelling (2016) is a prime example of an overlooked medium-one that time appears to have forgotten-but one that as he argues has greatly affected literature, has received important influences from literature and whose historical overview can provide great insight to sociocultural and literary workings today.

6 Porter's concise and highly informative Introduction sets the ground work for extensive interpretive accounts of specific case studies throughout the book. The Introduction offers a detailed account of early radio history, with references to CBS and $\mathrm{NBC}$, lists the significance of radio for the average American and delves into the literary ventures made through and by radio thus changing broadcast culture and posing as an enormous cultural impact on Americans. As a modernist invention, radio made the listener prominent and challenged modernist writers to devise new techniques via the characteristics of the radio medium. In fact, as Porter emphasizes, radio held such an integral place in American culture between the 1920s-30s as it "held the nation together during the Depression years by offering listeners a shared experience; [...] [and] "constructed 'imagined communities"' (5). Building on prior studies, Porter seeks to "explore the way modernism was absorbed by radio and seeks to understand how 
literary textualities contributed to the prestige movement in radio during the mid-1930s through the 1940s and beyond" where for a brief moment "sophisticated forms of storytelling [mixed] with prevailing forms of popular radio" thus resulting in "literary-savvy productions, which in turn posed new aesthetic challenges for broadcasting" (7). Porter goes on to cite the area of tension in radio, namely that of word-centered and sound-centered storytelling where phonophobia was dealt with via the mastering effect " $\mathrm{t}] \mathrm{h}$ he aim of which was to restrict aurality to the letter of language in order to preempt any slippage between sound and sense" (8). As Porter highlights, modernism vitalized radio, thus allowing for what he terms acoustic drift resulting in acoustic depth and density which drew attention to the radio as medium but also fostered innovative and experimental modernist storytelling practices. The book, comprised of eight chapters, combines descriptive and interpretative accounts of radio storytelling in a chronological order thus additionally providing a historical and sociocultural account of both radio broadcast culture and radio storytelling.

Chapter one focuses on the literary turn in radio which though willing to embrace the disruptive side of sound, acoustic drift was not entirely welcome by network programming despite the fact that it would be the key to unlocking the hidden power of sound (9). In a chapter highly reminiscent of iconophobia in regards textual literary adaptation to film, Porter examines the respective phonophobia evident in the adaptation of literary works to radio. The main concern was "the uncoupling of sound from sense" where sound, or rather noise, by those of a logocentric mentality, saw any acoustic item not directly corresponding to word-sense as "violating broadcast rules of decorum." Porter, however, insightfully argues how this acoustic deviance - being on the fringe of acoustic drift is highly intense, as the meaning of sounds has not been fixed, signified or stabilized. In other words, as opposed to "mastering the effect" of daytime radio soap-opera broadcasts-highly perfected by Frank and Anne Hummertacoustic divergence provided the experimental space to explore the narrative and medium capabilities and possibilities of radio which led to its literary turn. Instead of conforming to patterns where dialogue was recited with little to no sound, sound effects and enunciation was key, night-time radio broadcasts of serious drama and highbrow literary content paved the way for the "prestige" movement; a movement which clearly demonstrated the "magic of radio."

Chapter two investigates the maturation of radio as well as its storytelling capabilities by focusing on the debut of the Columbia Workshop (CBS) in 1936 which included an acclaimed array of works such as Archibald MacLeish's The Fall of the City (1937) and Air Raid (1938), Norman Corwin's They Fly through the Air (1939) and On a Note of Triumph (1945), and Vic Knight's Cartwheel (1945) to name but a few. This chapter emphasizes the hybrid nature of radio, placing emphasis on its avant-garde and modernist narrative capabilities as well as the technological potential of the medium which the broadcasting networks saw as a means to draw audience attention by raising awareness towards the medium in a metanarrative way. While the chapter divulges political reasons which prompted radio broadcasters to venture towards improving the quality of their programming, the programs themselves-with their mosaic, experimental and even self-referential capacities-actually displayed how radio broadcast need not be viewed as something popular and without substance (much like comic books were viewed until the appearance of the graphic novel). In fact, it was inventive radio auteurs who rescued broadcast culture with their creative output. This ultimately led to what is known as "Prestige radio" thus deeming CBS not only a broadcaster but a 
publisher of "literature of the air" and paved the way for creative geniuses such as Orson Welles.

Chapter three follows up on the Columbia Workshop and prestige radio by focusing more specifically on the contribution of Orson Welles's "subversive radio genius, which lay in creating narrators who fragmented the authorial perspective into multiple voices" (10). Porter provides a detailed and concise account of the two main literary works Welles adapted for radio, Dracula and War of the Worlds. In the former, the chapter breaks down how Welles successfully manages to deconstruct the novel's focus on the written word and print-a novel which is essentially anti-radiophonic-by subjugating it with the voice of the master only to never let the message arrive. The notion of unreliable narrators is further pursued in Welles's latter adaptation where the lines of fiction and fact were blurred, entertainment was mistaken for real news whilst Welles beat Marshall McLuhan's "tribal drum" to awaken the masses that had already begun viewing radio as reliable, newsworthy and trustworthy in its broadcasts of World War II. Inevitably confirming the hoax played on the audience, Welles-as Porter confirmswas more interested in the dynamics of representation in radio than in the history. Welles's genius became evident in his ability to "exploit the tension between sound and sense" while his brilliance in handling the literary capabilities of radio appear in how Welles treated the gap "between acoustic chaos and literary meaning-making" (81). Welles denied any radio voice the final say, thus setting a new trajectory (90).

Chapter four moves on to focus on Edward R. Murrow-the founding father of broadcast journalism and inventor of the radio essay. Murrow who "pledged to live dangerously, to be near ground zero, documenting the everyday details of death and survival" (91) of the Blitz, used the news commentator not to blur fact and fiction like Welles but to "suggest a measure of false authority" so as to redefine radio authenticity through first-hand accounts (86). Murrow's style, considered to be a literary feat, functioned in a way that meant to evoke the participatory sense of history [through his essays] that would infiltrate the collective mind of a United States with deep-seated isolationist prejudices" (10). In addition to being instantaneous, going beyond the facts and enriching events with metaphor, irony and high drama, Murrow highly sought out the "close-ups of acoustic events"-much like the film close-up; this proximity effect allowed him to bridge the geographical gap between London and listeners anywhere else whilst also feeding into the acoustic atmosphere he was intent on creating. In order to highlight the strange, the otherness of war, Murrow heavily relied on the notion of selective listening and isolating the aural signifier from its signified thus obscuring modes of perception and meaning. In other words, being that close to the source of sounds was analogous to being near the origin of meaning itself (103).

11 Meanwhile, chapter five fascinatingly draws an analogy between the problem of the speaking woman through the example of Betty Wason and the myth of Narcissus and Echo, the latter who is coined as an "acoustic mirror" capable only of repeating fragments of sounds. The myth essentially symbolizes "women's own devocalization and disembodiment by patriarchy and the symbolic order" (106) thus confirming the gender inequities and prejudices against the female voice in both film and radio. Radio proved inhospitable to the female voice in nonperforming roles, [a] bias [that] was not confined to network policy" (11). Nevertheless, Wason, who worked with Murrow, also found herself at the front lines reporting the news and was intent on doing so until "network bosses banned her voice outright" (107). This is also evident as Porter 
informs in CBS's long-running prestige anthology Suspense dedicated to horror and specializing in desperate, hysterical females who were essentially permitted "shudders, whimpers, screams and cries" (109). Women in radio in the 1940s came to signify the scream, a moment existing outside of "language, time and the conscious subject," "where speech is suddenly extinct, a black hole, the exit of being' (110). Focusing in more detail on the episode Sorry, Wrong Number (1943), Porter demonstrates how an inadvertent eavesdropper, Mrs. Stevenson, yet another screaming, paranoid, neurotic woman resonated her agony to the audience who may have ultimately wished for her voice to be silent but overall were drawn to the episode nonetheless, thus confirming its popularity. As Porter states, the screaming female voice is capable of disturbing "the apparently natural relations between language and meaning" (120). Unsurprisingly influencing Hollywood film adaptations, Porter concludes the chapter by highlighting the "outsider" female voice, one that unmasked the gender dynamics of modernist radio and posed as a threat but was a voice prestige radio couldn't do without (126).

Chapter six examines the common point of reference between Dylan Thomas and Samuel Beckett "whose interest was in defying radio's ontological borders by flirting with the disruptive properties of sound" (11). Dylan Thomas was the Orson Welles of the BBC a decade later. With his works, one of the most notable being Under Milk Wood, aurality became extreme, intense musicality characterized the piece and "radical worldplay [...] called attention to the materiality of language" (130). Thomas through his signature "personal reminiscence" unleashed the subversive side of language, employed figurative aspects such as puns, alliteration, assonance and onomatopoeia thus elevating sound-making over sense-making. While Under Milk Wood is conceived as a genre unto its own it brings the aurality of language to the forefront while "withdrawing from the insistence of meaning" (139) thus deeming the text of the ear and enriching the aesthetics of prestige radio. Samuel Beckett's partnership with the BBC which would last nearly a decade, brought about, among others, All That Fall (1957). This was a testament to how Beckett acknowledged the unique capabilities and power of radio to the point where he refused to have any of his works written for radio produced for theatre. True to the avant-garde spirit, Beckett insisted all sound be treated surrealistically as he wished "to place imaginative demands on listeners by dividing acoustic signals from their signs, making it difficult to identify [...] their 'sonorous sources"' (152). Although both Thomas and Beckett exhibit aesthetic differences, their converging point in regards radio lies in "resisting the transparency of language-as-word;" they sought the "disturbing power of sound" where Beckett seeks to liberate word from speech essentially deeming the voice sound (and not speech), while Thomas with excess sound "dramatizes the arbitrariness of signification" (154). As Porter confirms, both took revenge on the logos for having devocalized language" (154).

In chapter seven Porter, focusing on radio as music, demonstrates how Canadian pianist Glenn Gould radically redefined the experience of the listener by subverting the conventional aesthetics of documentary radio via modernist collage-like techniques and managed to move a speech-centered genre in the direction of pure musicality" (11). Following up on the previous chapter, Gould assisted in musicalizing the human voice thus taking "the radio drama of Dylan Thomas and Samuel Beckett to the point of no return" (155). In spite his early death, Gould left a legacy of a remarkable body of works, the most prominent as Porter points out being The Solitude Trilogy (1967-77). Comparing his radio work to Bach, Gould defined his unique approach to sound as 
"contrapuntal" in other words, "weaving voices in and out as a composer might write lines of music in a fugue" (156). Porter examines Gould's "The Idea of North -a kind of Arctic Under Milk Wood-which is technically a documentary and rather unorthodox at that exhibited Gould's musical interpretation of voice. Gould communicated his idea of the North via cutting, splicing and layering interviews into "a complex vocal 'docudrama"' (161). In an attempt to avoid the straight-forward and monologic mentality of radio, Gould highlighted polyphony and strived for a "multitrack consciousness" (165) which as Porter explains resulted in an intertextuality in the spaces between the speakers where Gould effectively neutralizes meaning (169). Gould's follow up project "The Latecomers" (1968) picks up where "The Idea of North" leaves off and privileges sound over human voice. Gould completed his study of solitude with "The Quiet in the Land" the most technologically complex of the three pieces essentially emphasizing the need for deeper, more attentive listening experiences due to the technological advances and experimentations done in radio programming. If anything, Gould poses as yet another cog that assisted in the evolution of sound, radio, and storytelling.

14 The final chapter leaves room for National Public Radio's (NPR) All Things Considered which adopted a "magazine" format and indulged listeners with an inventive mix of news, commentaries, satire, essays, plays and mini-documentaries resulting in a cult following (12). Porter focuses on the Founding Mothers, such as Susan Stamberg who was to NPR what Edward R. Murrow was to CBS. Reference is also made to Bill Siemering, NPR's first program director and creator of All Things Considered. Siemering's contribution and mentality proved highly significant as he wanted to expand listener experience "with many voices and many dialects" whilst advancing "the art and the enjoyment of the sound medium" (186). Porter delves into the witty and satirical monologues of Jean Shepherd, the naturalist Kim Williams, as well as Sarah Vowell and David Sedaris to name but a few. NPR, as Porter informs was known at that time (1970s) as diverse, focusing on the cultural side of public radio targeting arts and heterogeneity through its unique "outsider" voices and commentators. In attempts to promote cultural and journalistic storytelling, there was "no master narrative, no dominant spokesman" (194). NPR, now deemed too mainstream and too deferential to power, at that time sought authenticity and was anti-authoritarian (194-95). Experimental storytelling was achieved via Joe Frank, the "Apostle of Noir Radio" and Ken Nordine; as Porter puts it: "an absurdist in another vein, Ken Nordine is the Calvino to Frank's Kafka, comic where Frank was bleak" (203). And yet, in spite such progress, innovation and experimentation NPR in the 1980s fell victim to the payroll and mainstreaming. Fortunately, creative work exists elsewhere; Porter informs that This American Life (1995-present) has assisted in keeping long-form radio storytelling alive (208) but at the cost of poetry and fiction being largely absent from the new radio mix and the achievements of modernist broadcast radio posing more as a faded fascination we look back on with nostalgia.

While the oscillation between speech-centered and sound-centered scope and features and the appearance of media such as the television and today's internet culture, radio has more or less been overlooked. And while it may appear that we are living in a visual culture, multitrack videos and podcasts do raise attention and awareness to media such as the radio. Perhaps, as Porter and Charles Bernstein suggest, it is time for not only "close reading," and I would add "close viewing" but also "close listening" a practice which entails "multitrack-like attention to the acoustic and nonacoustic layers that 
make up the 'total' of radio work" (13-14). Porter successfully presents excerpts of dialogue, extensive descriptions and interpretations, referencing Marshal McLuhan among others, to argue and highlight that radio was and is capable of storytelling. Radio had and still has the potential to experiment with sound, language, voices, narrators, music, editing, and enrich the multimedia landscape we currently live in with an added and unique perspective. Perhaps it is time for such a practice, which has been lacking to the extent and degree it did in the past, to reappear for more effective communication and storytelling in an age overrun by the visual.

\section{AUTHOR}

KATHERINE MARAZI

Aristotle University of Thessaloniki, Greece 